\title{
Reprocessing of Multi-channel Seismic-Reflection Data Collected in the Chukchi Sea
}

by W.F. ${ }^{1}$ Agena, M.W. Lee ${ }^{1}$, and P.E. Hart ${ }^{2}$

Open-File Report 01-330

2001

This report is preliminary and has not been reviewed for conformity with the U.S. Geological Survey editorial standards or with the North American Stratigraphic Code. Any use of trade names is for descriptive purposes only and does not imply endorsement by the U.S. Government.

\section{U.S. DEPARTMENT OF THE INTERIOR}

\section{U.S. GEOLOGICAL SURVEY}

1 U.S. Geological Survey, MS 939, Box 25046, DFC, Denver, Colorado 80225

2 U.S. Geological Survey, MS 999, 345 Middlefield Rd, Menlo Park, CA 94025 


\begin{abstract}
Contained on this set of two CD-ROMs are stacked and migrated multi-channel seismicreflection data for 44 lines recorded in the Chukchi Sea, northern Alaska, by the United States Geological Survey in 1977, 1978, and 1980. All data were reprocessed by the USGS in 2000 using updated methods. The resulting final data have both increased temporal and spatial resolution thus providing improved interpretability. An added benefit of these CD-ROMs is that they are a more stable, long-term archival medium for the data.
\end{abstract}

\title{
CONTENTS OF CD-ROM
}

Each of the two CD-ROMs contains the following files: 1) 44 files containing the digital seismic data in standard, SEG-Y format; 2) 1 file containing navigation data for the 44 lines in standard SEG-P1 format; 3) an ASCII text file with cross-reference information for relating the sequential trace numbers on each line to common depth point (CDP) numbers and shotpoint numbers; 4) 2 small scale graphic images (stacked and migrated) of a segment of line 705 in Adobe Acrobat $^{\circledR}$ 5.0 PDF format; 5) an Adobe Acrobat ${ }^{\circledR} 5.0$ PDF format graphic image of the location map, generated from the navigation file; 6) PLOTSEIS, an MS-DOS application that allows users of IBM-compatible personal computers to interactively view the SEG-Y files; 7) a PLOTSEIS documentation file; and 8) an explanation of the processing used to create the final seismic sections (this 
document). Additional copies of this publication can be obtained by calling 1-888-ASKUSGS (1-888-275-8747).

\section{DATA ACQUISITION}

These data were collected in the Chukchi Sea from 1977 through 1980 aboard the USGS research vessel Samuel P. Lee. Shown in Table 1 is a listing of the lines and their recording vintages. The recording system used was a Globe Universal Sciences (GUS) ${ }^{\circledR}$ model 4200, recording 24 channels at a 2-millisecond sample rate. A tuned array of five air-guns totaling 1326 cubic inches was used as the seismic energy source and was fired at 50-meter intervals. The receiver array consisted of 24 groups of hydrophones spaced at 100-meter intervals, for a total array length of 2400 meters. Recording lengths varied between 6 and 7 seconds sub-seafloor with deep-water recording delays implemented over the continental slope and rise. Positioning of the survey was achieved using a Marconi integrated satellite-doppler sonar navigation system. Figure 1 is a map of the tracklines of the survey area.

\section{DATA PROCESSING}

All data were reprocessed using the ProMAX ${ }^{\circledast}$ seismic data processing system using methodologies described by Yilmaz (1987). Processing sequences and parameters used by Leinbach and others (1987), Lee and others (1998), and Miller and others (2000) provided a useful starting point for designing the processing sequence used for this data 
set. The following is a summary of the objectives and parameters of our processing sequence. In reprocessing these data, we were unable to recover shotpoints (SP) 42237540 of line 19. See Figure 1 and Table 1 for additional details.

\section{Geometry Definition}

All data were previously demultiplexed and resampled to 4-ms by Grantz and others (1982) and only needed to have a geometry definition applied prior to sorting the data into Common Midpoint (CMP) order. Defining the source and hydrophone locations, station numbers, distance between stations, and distance between shots is necessary to correctly describe the recording geometry.

\section{Static Corrections}

Typically in marine surveys, time delays are introduced into the recording system, particularly over deep water in order to conserve recording media. In processing the data, static corrections are necessary to account for these time delays.

\section{Automatic Gain Control}

Some form of gain recovery is typically applied to raw field data to compensate for the effects on amplitude by wavefront divergence and the Earth's usual attenuation properties. Because one of the primary goals of our study was structural rather than 
stratigraphic interpretation, preserving relative amplitudes was not a primary concern. Therefore, we opted to use a simple automatic gain control function using a 350millisecond sliding time gate.

\section{Deconvolution (Pre-Stack)}

To increase temporal resolution and, sometimes, to remove the effects of multiples, deconvolution is applied before stack. In our processing, we employed a single-window, minimum-phase spiking deconvolution with a 160-millisecond operator length, with good results.

\section{F-K Shot-Domain Filtering}

These data were recorded in relatively shallow water and exhibited a significant amount of noise that appeared linear when stacked. In combating this noise, we designed and applied two-dimensional frequency-wavenumber (F-K) filters in the shot-domain as described by Lee and others (1998).

\section{Velocity Analysis and NMO Corrections}

Conventional velocity analysis panels, which included semblances, gathers, and constant velocity stacks, were used to estimate optimum stacking velocities. Analyses were 
generated at $100 \mathrm{CMP}$ intervals. Results from the velocity analyses were then used to apply normal moveout (NMO) corrections to the data.

\section{Trace Weighting}

A simple technique used to suppress multiples is to apply a weighting function to traces within a CMP, prior to stacking. We applied a weighting factor based on the absolute offset of the trace. By doing this, we amplify the effects of differential moveout between primaries and multiples, thereby decreasing the contribution of multiples to the stacked output.

\section{Stack (12-Fold)}

The objective of horizontal stacking is to reduce the effects of random signals or enhance the signal-to-noise ratio. Our processing included the application of a straight mean value CMP stack, where values at a given time are summed and then divided by the square root of the number of values. This survey had a nominal 12 -fold coverage.

\section{Post-Stack Deconvolution and Wavelet Processing}

Following the CMP stack there still remained some reverberatory energy. To minimize this noise we implemented a second-zero crossing deconvolution using a single window with an 180-millisecond operator. This is a type of predictive deconvolution where the 
second-zero crossing of the auto-correlation function of the trace is used as the predictive "gap." Prior to the application of the second-zero crossing deconvolution, we applied automatic gain control using a 1000-millisecond sliding gate. Additionally, to further increase temporal resolution, we applied wavelet processing using the variable norm deconvolution method described by Gray (1979). For each line, careful wavelet analysis was performed, and a single operator derived from the optimum parameters was applied to the entire line.

\section{F-K Migration}

The objective of migration is to move (migrate) data from an observed point of reference to a point of actual origin. Implemented ideally, this procedure essentially collapses diffractions to a single point, and spatially orients dipping events to their correct position. These data were migrated using the Stolt wave-number frequency (F-K) method with velocity models derived from our stacking velocities. Shown in Figures 2 and 3 is a segment of line 705 before (Figure 2) and after (Figure 3) F-K migration.

\section{Data Output}

Following migration, the data were stored in the industry-standard SEG-Y format (Barry and others, 1975). In order to fit all the data onto two CD-ROMs, the data were written in 2-byte integer form rather than the usual 4-byte $\mathrm{IBM}^{\circledR}$ real. Shotpoint numbers were written into trace headers using a 4-byte integer word starting at byte 181 . 


\section{SYSTEM REQUIREMENTS}

These discs will operate on any hardware platform capable of reading the ISO 9660 standard. The seismic data files are disc images of the SEG-Y format (Barry and others, 1975). The display programs and other software packages can access the data files directly from the CD-ROM. Technical information is contained in files in ASCII text, Adobe Acrobat ${ }^{\circledR}$ 5.0 PDF and HTML formats. Graphics files are contained in Adobe Acrobat ${ }^{\circledR}$ 5.0 PDF format. Minimum hardware/software requirements are as follows:

All platforms: CD-ROM drive with ISO 9660 software driver, software capable of reading SEG-Y format data files, ASCII text files, and PDF-format graphics files. Technical information can also be accessed by software capable of reading Adobe Acrobat $^{\circledR}$ 5.0 PDF or HTML formatted files.

IBM-compatible P/C: To use the display software: $640 \mathrm{~K}$ main memory, hard (fixed) disk, monochrome monitor, EGA/VGA/SVGA graphics, MS or PC-DOS 3.1 or higher. An IBM P/C compatible seismic display program, PLOTSEIS.EXE (Zihlman 1996), is included on this disk for the purpose of displaying the SEG-Y data files. Users should follow the installation/operating instructions contained in the documentation file PLOTSEIS.TXT. To run PLOTSEIS directly from the CD-ROM, it may be necessary to specifically type the path name without a backslash character. For example, if the drive letter is Z, the default path will appear, as "Z:l", but you should type "Z:" only. Thereafter a menu of files will appear on the screen. You can then select a ".sgy" file 
and display the traces on the screen. No display software is provided for non-PC compatible systems.

\section{SUMMARY AND CONCLUSION}

The processing methodology described here resulted in seismic profiles with increased temporal and spatial resolution, which should facilitate more accurate interpretation of the data. Writing these data to CD-ROM provided two-fold benefits over older methods. Firstly, the data are in a compact, easy-to-use format allowing quick, random access and the ability to easily load the data onto a computer interpretation workstation. Secondly, the data are now on an archival medium that is much more stable than the previously used magnetic tape, thus ensuring a longer lifespan. These CD-ROMs complement the Beaufort Sea CD-ROM data set previously published by Agena and others (2000).

\section{DISCLAIMER}

This Compact Disk (CD) publication was prepared by an agency of the United States Government. Neither the United States Government nor any agency thereof nor any of their employees makes any warranty, expressed or implied, or assumes any legal responsibility for the accuracy, completeness, or usefulness of any information, apparatus, product, or process disclosed in this report or represents that its use would not infringe privately owned rights. Reference therein to any specific commercial product, process, or service by trade name, trademark, manufacturer, or otherwise does not 
necessarily constitute or imply its endorsement, recommendation, or favoring by the United States Government or any agency thereof.

Although all data and software published on this CD-ROM have been used by the USGS, no warranty, expressed or implied, is made by the USGS as to the accuracy of the data and related materials and(or) the functioning of the software. The act of distribution shall not constitute any such warranty, and no responsibility is assumed by the USGS in the use of these data, software, or related materials.

\section{FIGURES}

Figure 1. Digital image in Adobe Acrobat ${ }^{\circledR}$ 5.0 PDF format containing tracklines of the Chukchi Sea seismic survey.

Figure 2. Digital image in Adobe Acrobat ${ }^{\circledR}$ 5.0 PDF format of line 705 unmigrated and stacked.

Figure 3. Digital image in Adobe Acrobat ${ }^{\circledR}$ 5.0 PDF format of line 705 after migration.

\section{TABLES}

Table 1. Listing of recorded line numbers and the year in which they were recorded. 


\section{REFERENCES}

Agena, Warren F., Lee, Myung W., and Hart, Pat E., 2000, Reprocessing of multichannel seismic reflection data collected in the Beaufort Sea: U.S. Geological Survey Open-File Report OF\# 00-460, CD-ROM

Barry, K.M., Cavers, D.A., and Kneale, C.W., 1975, Recommended standards for digital tape formats: Geophysics, v. 40, p. 344-352.

Grantz, Arthur, May, S.D., and Mann, D.M., 1982, Tracklines of multichannel seismicreflection data collected in the Beaufort and Chukchi Seas in 1977 for which demultiplexed field tapes are available from the U.S. Geological Survey: U.S. Geological Survey Open-File Report OF\# 82-0651, 1 over-size sheet, scale 1:500,000.

Gray, W.C., 1979, Variable norm deconvolution: Palo Alto, CA, Stanford University Ph.D. Thesis, $101 \mathrm{p}$.

Lee, Myung W., Agena, Warren F., Grow, John A., and Miller, John J., 1998, Seismic processing and velocity analysis in The ANWR Assessment Team, The Oil and Gas Resource Potential of the 1002 Area, Arctic National Wildlife Refuge, Alaska: U.S. Geological Survey Open-File report OF\# 98-34, CD-ROM, p. SP1-SP32.

Leinbach, W. James, Miller, John J., and Lee, Myung W., 1987, Seismic reflection data processing in Bird, Kenneth J. and Magoon, Leslie B., eds., Arctic National Wildlife Refuge, northeastern Alaska: U.S. Geological Survey Bulletin 1778, p. 225-233. Miller, John J., Agena, Warren F., Lee, Myung W., Zihlman, Frederick N., Grow, John A., Taylor, David J., Killgore, Michelle, and Oliver, Harold L., 2000, Regional 
Seismic Lines Reprocessed Using Post-stack Processing Techniques: National Petroleum Reserve - Alaska: U.S. Geological Survey Open-File Report OF\# 00-286, CD-ROM.

Yilmaz, Ozdogan, 1987, Seismic data processing: Society of Exploration Geophysics -Investigations in Geophysics, v.2, 526 p.

Zihlman, F.N., 1996, PLOTSEIS, A DOS display program for SEG-Y formatted seismic data: U.S. Geological Survey Open-File Report OF\# 95-516, 7p., 1 - 3/1/2" disk. 


\begin{tabular}{|c|c|}
\hline Line Number & Year \\
\hline 7 & 1980 \\
\hline 8 & 1980 \\
\hline 9 & 1980 \\
\hline 10 & 1980 \\
\hline 11 & 1980 \\
\hline 13 & 1980 \\
\hline 18 & 1980 \\
\hline $19 * *$ & 1980 \\
\hline 20 & 1980 \\
\hline 21 & 1980 \\
\hline 22 & 1980 \\
\hline 23 & 1980 \\
\hline 24 & 1980 \\
\hline 702 & 1977 \\
\hline 703 & 1977 \\
\hline 704 & 1977 \\
\hline 705 & 1977 \\
\hline 706 & $\begin{array}{l}1977 \\
\end{array}$ \\
\hline 801 & 1978 \\
\hline 802 & 1978 \\
\hline 803 & 1978 \\
\hline 804 & 1978 \\
\hline 805 & 1978 \\
\hline 806 & 1978 \\
\hline 807 & 1978 \\
\hline 808 & 1978 \\
\hline 809 & 1978 \\
\hline 810 & $\begin{array}{l}1978 \\
\end{array}$ \\
\hline 811 & 1978 \\
\hline 812 & 1978 \\
\hline 813 & 1978 \\
\hline 814 & $\begin{array}{l}1978 \\
\end{array}$ \\
\hline 815 & 1978 \\
\hline 816 & 1978 \\
\hline 817 & 1978 \\
\hline 818 & 1978 \\
\hline 819 & 1978 \\
\hline 820 & 1978 \\
\hline 821 & 1978 \\
\hline 822 & 1978 \\
\hline 823 & 1978 \\
\hline 824 & 1978 \\
\hline 825 & 1978 \\
\hline 826 & $\begin{array}{l}1978 \\
\end{array}$ \\
\hline
\end{tabular}

Table 1. - Listing of recorded line numbers and the year in which they were recorded. **Data from line 19 are incomplete. We were unable to recover the data from Shotpoints 4223 through 7540 